ISBN 978-93-84422-76-9

5th International Conference on Food, Agricultural, Biological and Medical Science

(FABMS-2017)

Bangkok (Thailand) Feb. 6-7, 2017

\title{
Hydroponics Effluents: A Potential Threat To The Environment
}

\author{
Dr Prathima Seechurn Poonpoon, Indoomatee Ramma, and Dr Bhanooduth Lalljee \\ University of Mauritius/FAREI
}

\begin{abstract}
Hydroponics culture is an innovative method of foodcrop production that helps to increase productivity and produce quality. The system of hydroponics commonly used in Mauritius is the open (run to waste) system where the substrate is continually supplied with fresh nutrients while the old is removed from the substrate by the drainage system as waste. However, hydroponics growers are mainly interested with the production side and often ignore the environmental risk associated with the waste discharged from their cultivation. This study was carried out to assess how many hydroponics growers in Mauritius are aware of the environmental impact caused by open hydroponics cultures. 120 hydroponics growers were selected for a survey around the island. $96 \%$ of the hydroponics growers claimed that they were not aware of the pollution caused by waste water discharge from their open hydroponics cultivation while only $4 \%$ of the growers were found to be aware of environmental impact of hydroponics effluents and these growers collected the hydroponics effluents discharge and used them to irrigate garden crops. They even designed a system for collection of their hydroponics effluents. From data collected during the survey, it was also estimated that under normal conditions, out of $100 \mathrm{~mL}$ of nutrient solution provided per plant, around 60\% of solution was absorbed by the plant and the rest leached out as hydroponic effluent. The amount of hydroponic effluents collected per day from one greenhouse was around 1 litre per square metre with a nitrate concentration of around $108-110 \mathrm{mg} / \mathrm{L}$. The concentration was found to vary with the crop density and size of greenhouses. Assuming that on average 250 litres of hydroponic effluents were leached per day, the amount of nitrate lost for a greenhouse of $250 \mathrm{~m}^{2}$ was 27 $g$ per day. Furthermore, for crops like tomato the amount of nitrate discharged in the environment was estimated to around $6000 \mathrm{~g}$ per square metre over one year period. . Thus, for Mauritius with an estimated area of 25 hectares under open hydroponics, it was forecasted that $26 \mathrm{~kg}$ of nitrate would be lost to the environment per day
\end{abstract}

Keywords: pollution, environment, hydroponic effluents, excess fertiliser, leaching

\section{Introduction}

Water is a scare resource of vital importance. The increasing need for water supplies make it imperative to improve or develop new approaches to reuse non-conventional water resources. Wastewater is one alternative that can be considered. Wastewater contributes some $2,400 \mathrm{~kg}$ of organic matter per hectare, $195 \mathrm{~kg} / \mathrm{ha}$ of nitrogen and $81 \mathrm{~kg} / \mathrm{ha}$ of phosphorus to the soil (Cutolo, 2012). Wastewater irrigation is a source of water recycling and it provides a source of $\mathrm{N}$ that can provide for plant nutrition needs and increase crop yields (Cutolo, 2012). Any type of wastewater is likely to cause environmental damage. Wastewater effluents if properly used can make a good contribution to water conservation and expansion of irrigated agriculture, taking on an economic dimension. It also solves disposal problems aimed at protecting the environment and public health by preventing surface water pollution (Mkude, 2014). The degradation if occurs by improper disposal of the effluents is often related to the presence of organic and inorganic nutrients, which cause problems such as eutrophication and algal blooms. Hydroponics effluents are nutrient-rich wastewater discharged from open hydroponics culture. Their discharge in the environment can undoubtedly be a significant source of pollution in the coming years given the increasing number of new hydroponics structures set up yearly. Thus possibly requiring regulatory measures to be put in place to control the discharge of effluents and mitigate the environmental impacts. Given limited information of the impact of hydroponics effluents, this study focussed 
mainly on a survey conducted around the island to assess hydroponics growers' awareness of the environmental impact associated with the effluents. During the study the area under hydroponics production was around 25 hectares.

\section{Field Experiment}

Figure 1.0 shows the steps used for the selection of growers. The survey was carried out a mong 120 growers around the island. The sampling fram e was obtained from the Food and Agricultural Research and Extension Institute (FAREI).

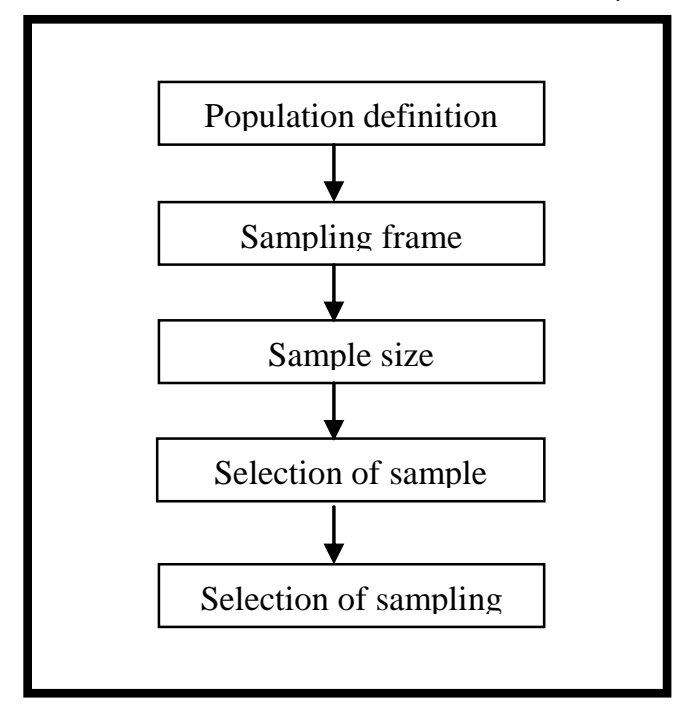

Fig. 1 Steps for selection of growers

The target population was separated into strata, which are non-overlapping groups. E ach stratum was represented by one of the four main regions na mely; North, South, E ast and Central Plateau. Within each of the region, growers were sam $\mathrm{pled}$ according to the proportionate allocation method. The target population consisted of 206 growers as a t $\quad \mathrm{M}$ a y 2009 . Table 1.0 below shows the method used to determine the sa m ple size in each of the four regions. Applying stratified random sampling within each stratum i mproves representativeness of the sample by reducing sampling error. A sam ple size of 120 growers was selected, representing a p proximately $58 \%$ of the target population.

TABLE I: Method for obtaining sample size for each region

\begin{tabular}{|l|l|l|l|l|}
\hline Stratum & $\begin{array}{l}\text { No of } \\
\text { growers }\end{array}$ & $\begin{array}{l}\text { Number } \\
\text { of } \\
\text { growers } \\
\text { at } 58 \%\end{array}$ & & $\begin{array}{l}\text { Number of } \\
\text { growers } \\
\text { chosen from } \\
\text { each stratum }\end{array}$ \\
\cline { 1 - 3 } North & 60 & 35 & $\begin{array}{l}\text { Sample } \\
\text { size } \\
\text { chosen }\end{array}$ & 32 \\
\hline South & 34 & 20 & 16 \\
\hline
\end{tabular}




\begin{tabular}{|l|l|l|l|l|}
\hline East & 29 & 17 \\
\hline $\begin{array}{l}\text { Central } \\
\text { Plateau }\end{array}$ & 83 & 48 & $120)$ & 17 \\
\hline Total & $\mathbf{2 0 6}$ & $\mathbf{1 2 0}$ & 55 \\
& & \\
& & $\mathbf{1 2 0}$ \\
\hline
\end{tabular}

A set of standardised questionnaires was designed for the purpose of carrying out the survey. The questionnaire was meant to evaluate the growers' opinion as regards to the use of hydroponic effluents for alternative purposes. questionnaire was sub-divided into 4 sections n a mely; grower's profile, environ mental a wa re ness, hydroponics culture and waste manage ment. The survey has been carried out with the total approval of $t$ he respondents, in the most ethical possible way by respecting the confidentiality of the information g a the red.

\section{Data Analysis}

Descriptive analysis was performed using statistical program SPSS (statistical Package for the Social Sciences), version 12.0 and Excel software (Excel, Microsoft, 2007) to summarise data collected. Tables of figures, bar charts and pie charts were used to display the results. Some of the results were also expressed as percentages.

\section{Results}

\section{1) Demographic analysis}

Out of 120 growers surveyed, $89.2 \%$ were males and only $10.8 \%$ were females. The majority of the respondents $(61 \%)$ were in the range of 30-45 years age group and only $37 \%$ were in the $45-60$ years, this clearly indicates that hydroponics were the main influence on their business path. Out of the 120 growers surveyed, 67 (56\%) worked on a full-time basis in their greenhouses while the remaining 53 (44\%) worked on a part-time basis and had another job as their main occupation. The crops grown in the greenhouses were mainly tomato (68.3\%) followed by sweet pepper (15\%). Only 6 greenhouses were under cucumber cultivation.

\section{2) Environmental awareness}

On average 25 respondents mentioned that the state of the physical environment of their greenhouses was satisfactory and were well aware of the concept of sustainable development as compared to 52 respondents who stated that the state of the physical environment was satisfactory but yet they were not aware of the concept of sustainable development. A Pearson correlation test was carried out and it was observed that the correlation was significant at 0.01 levels (2-tailed test) between excess fertiliser and environmental problems.

\section{3) Hydroponics culture}

Most of the hydroponics growers were keen to invest in hydroponics production and tomato was the most widely grown crop. Figure 2.0 below depicts the reasons for choosing hydroponics production in which $56 \%$ highlighted that quality product was the main reason for starting hydroponics production. 


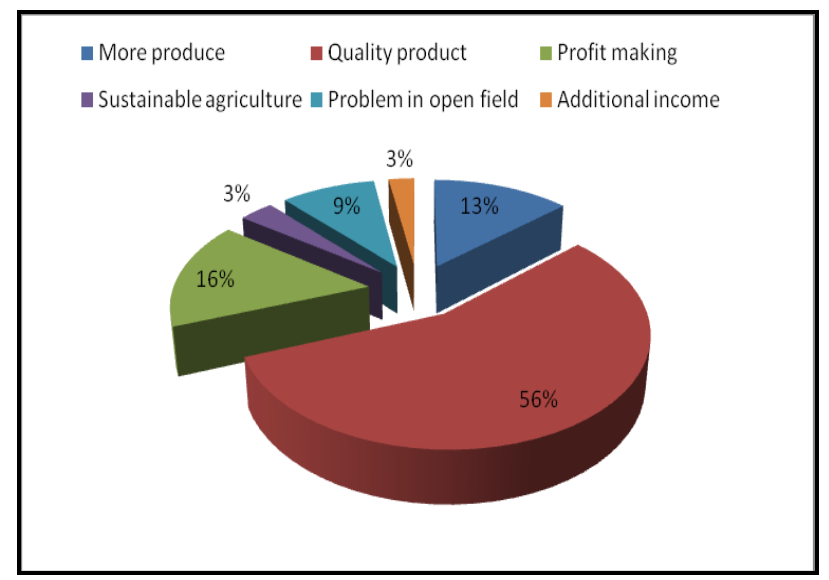

Fig. 2 Factors influencing growers' to invest in hydroponics production

\section{4) Waste Management}

Figure 3.0 indicates the growers' perception of risks associated with the improper disposal of hydroponic effluents as $96 \%$ of the target population was not aware of the environmental problems caused by hydroponic effluents and that only $4 \%$ of the growers usually collect the solution and use to irrigate other crops.

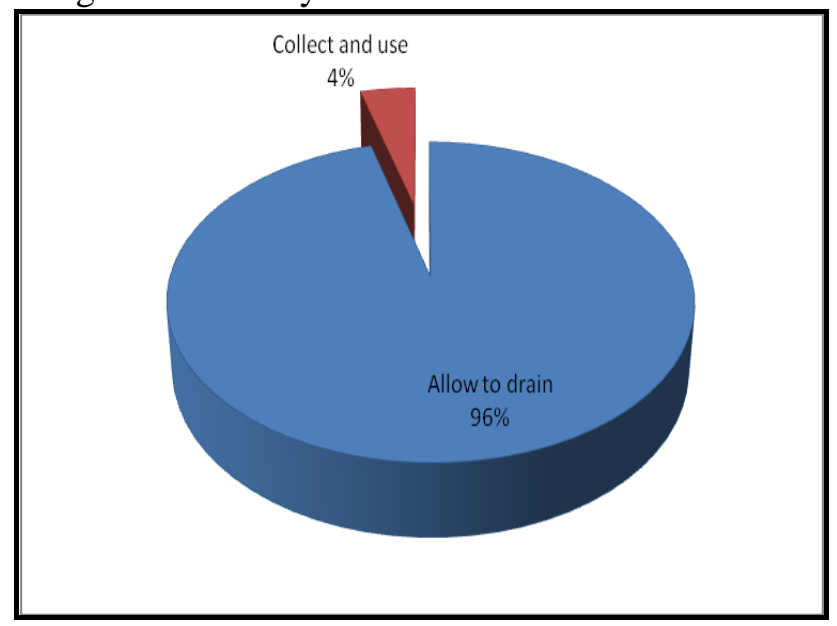

Fig. 3 Hydroponic effluents

$55.8 \%$ of the target population stated that their greenhouses generate 300-400 litres of hydroponic effluents per day, 35\% affirmed that 200-300 litres were lost per day and 6.7\% highlighted that 400-500 litres were lost per day. $2.5 \%$ of the respondents could not provide an opinion on this issue. According to the 120 growers interviewed, a majority (>90\%) predominantly were not aware of the nutrient content and economic value of the hydroponic effluents. $29.2 \%$ of the hydroponics growers accepted the idea of using the hydroponic effluents as a source of fertiliser while the remaining $70.8 \%$ were not aware of the use of the hydroponic effluents. Out of 120 respondents, 50 respondents stated that the use of hydroponic effluents need to be publicised thoroughly, 48 respondents highlighted that up to now no training facilities were provided, 20 respondents pointed out that the hydroponic effluents was difficult to collect and 2 growers were reluctant to answer and affirmed that information on hydroponic effluents were not available. On the other hand 57 respondents highlighted that the main factors to be considered while using the hydroponic effluents would be to protect the environment. 


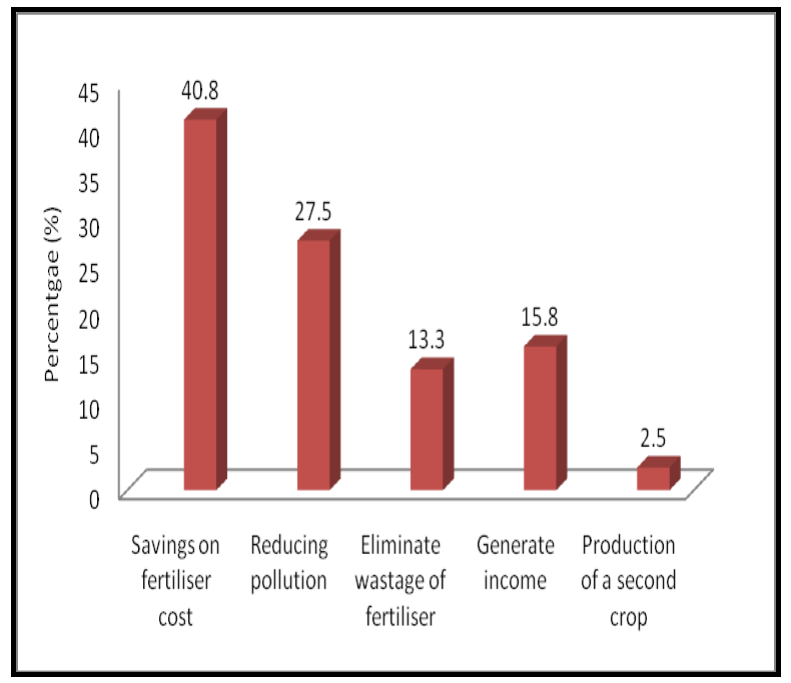

Fig. 4 Farmers' acceptance to use hydroponic effluents for crop production

Figure 4.0 above shows farmers' acceptance to use hydroponic effluents for crop production. Savings on fertiliser cost (40.8\%) was considered as the main concern. Other priorities were reducing pollution and income generation which scored $27.5 \%$ and $15.8 \%$ respectively. Furthermore, $13.3 \%$ of the growers claimed that the use of hydroponic effluents will help farmers to eliminate wastage of fertiliser. Overall, production of a second crop was not considered as being important for driving farmers to adopt this technology.

From data collected during the survey, it was also estimated that under normal conditions, out of $100 \mathrm{~mL}$ of nutrient solution provided per plant, around $60 \%$ of solution was absorbed by the plant and the rest leached out as hydroponics effluents. The amount of hydroponic effluents collected per day from one greenhouse was around 1 litre per square metre with a nitrate concentration of around 108-110 mg/L. The concentration was found to vary with the crop density and size of greenhouses. Assuming that on average 250 litres of hydroponic effluents were leached per day, the amount of nitrate lost for a greenhouse of $250 \mathrm{~m}^{2}$ was $27 \mathrm{~g}$ per day. Furthermore, for crops like tomato the amount of nitrate discharged in the environment was estimated to around $6000 \mathrm{~g}$ per square metre over one year period. Thus, for Mauritius with an estimated area of 25 hectares under open hydroponics it was forecasted that $26 \mathrm{~kg}$ of nitrate would be lost to the environment per day.

\section{Discussion}

Most of the respondents grew tomato $(68.3 \%)$. This clearly indicated that there was a certain level of reserve towards cultivating sweet pepper, cucumber and ornamentals, possibly due to causes such as personal choice, ease of marketing, higher profitability. Moreover, this fact was also in agreement with Passam (2008) who reported that tomato was the most important greenhouse crop worldwide. The survey has also revealed that hydroponics culture is a profit making business especially from big greenhouses reaching a total yield of 5 tonnes of tomato at Rs 70-120 per kg from a greenhouse of $400 \mathrm{~m}^{2}$ thereby recovering their initial investment in the first 2 years. Moreover, the produce obtained from greenhouses whether tomato, cucumber or sweet pepper were generally of good quality in terms of taste, appearance and size. This follows the growers' perception that as compared to open field cultivation, vegetables from hydroponics culture are usually not affected by pests, diseases and adverse climatic conditions which are in agreement with Rouphael et al. (2004) and that good quality product is as important as total yield in being competitive in modern horticulture. From the survey it has also been observed that despite the hydroponic solution prepared for tomato crop lasted for only 1-2 weeks as compared to sweet pepper crop which lasted for more than 2 weeks, most of the growers opted for tomato as it is usually in high demand locally.

More than $50 \%$ of the growers had more than two years of experience in hydroponics culture and had even more than one greenhouse. This shows the enthusiasm of local growers towards hydroponics production. As per the survey, only $26.7 \%$ of growers were aware of the concept of sustainable development (SD); hence efforts should be geared towards the sensitisation of growers. The lack of sensitisation/awareness could explain the unwillingness of growers to use the hydroponic effluents. When taking the concept of SD into consideration 
growers should either adopt the closed system or otherwise collect and use the hydroponic effluents in crop production. This fact hereby validates the importance of the present study.

Pollution by nitrate from agricultural activities has been extensively documented by many researchers; Campbell et al. (2006) mentioned that excess fertiliser from open field cultivation and hydroponics could lead to significant nitrate leaching and environmental pollution. Brady et al. (1999) highlighted that nitrate leaching from agricultural activities could also cause several environmental problems including the loss of calcium and other cations as well as moving into surface or groundwater where it can severely impact the quality of drinking water. Environmental pollution from hydroponics in terms of nutrients has also been reported by Fernandez (2009) and Gagnon et al. (2010). These facts have been supported by a survey carried out during the initial phase of the study whereby it has been found that 300-400 litres of drain out solution (hydroponic effluents) were lost per day from one greenhouse with nitrate values exceeding $50 \mathrm{mg} / \mathrm{L}$ (EPA, 1991).

Nevertheless, in Mauritius the problems associated with the discharge of hydroponic effluents, are ignored by growers as there is no Government regulation on hydroponic effluents from hydroponic cultures, hence they have no control upon the discharged volumes and they do not expect government also to be concerned over such environmental problems. However, due to its polluting potential, this may have a severe impact on the environment in the near future.

From the survey it can be deduced that $68.3 \%$ of respondents spent more than Rs $25,000 /$ - on fertiliser, this can to some extent be attributable to the crops under cultivation, which is associated with increased running cost annually. Moreover, growers could certainly make savings on fertiliser if they use the hydroponic effluents as an alternative source. As stated by Savvas et al. (2002b) and Carmassi et al. (2005) the savings of fertilisers may reach levels ranging between $40 \%$ and $50 \%$ of the total supply; the exact level of which depends on several parameters, such as the nutrient and water schedule, the crop species and the composition of the irrigation water used to compensate for plant water uptake (Varlagas et al. 2010). Growers overlooked the importance of using hydroponic effluents as a source of fertiliser since they were unaware of the economic value and nutrient content of the latter. With the rise in cost of fertiliser growers could however, manage and benefit from the 'free' nutrients in the hydroponic effluents, making full use of the latter thereby reducing the cost of purchasing inorganic fertiliser inputs accordingly (Tattini 1993) and at the same time adding value to the production of a second crop. Moreover, the use of hydroponic effluents could be considered as a sideline activity in Mauritius whereby the aim would not be solely for increasing profit but also protecting the natural environment as reported by Keller et al. (2005). Overall, the survey indicates that hydroponic effluents as a source of fertiliser, may however be seen as a potential alternative to be exploited in the local context.

To ensure proper coordination in hydroponics production, legal support is required so that every stakeholder has a well-defined course of action. Growers need to be made aware of the existing environmental laws which need to be amended and that they do not build preconceived ideas that hydroponics growers are free to unconventional practices in their quest to maximise productivity, at the expense of natural environment safety.

\section{Conclusion}

Since there are no regulatory measures for the control and discharge of hydroponics effluents, hydroponics growers just dispose the hydroponics effluents the way they wish. The study gives an indication of how many farmers adopt this bad practice and at the same time quantifying the amount of hydroponic effluents that can cause environmental pollution. The survey has also demonstrated that management of excess nutrients generated from hydroponics culture is influenced by a number of factors including the type of crops being cultivated and the provision of training in nutrient management. Overall, growers who wish to use hydroponics effluents should be provided with the necessary information and back up which will obviously increase their margin of profit. At the same time they can keep records about results obtained in order to monitor their productivity. This practice would however, reflect the commitment of growers to implement on-farm good management practices for making savings on fertiliser, which is a valuable ingredient in crop production.

\section{Acknowledgment}

The present work was partially supported by the Food and Agricultural Research and Extension Institute (FAREI), Mauritius. The project was also sponsored by the Mauritius Research Council (MRC). 


\section{References}

[1] Brady Nyle et al., (1999). The Nitrate leaching problem. In: Nature and Properties of Soils, 12th edition, pp502-503.

[2] Campbell. C. A et al., (2006). Nitrate leaching in the semiarid prairie: Effect of cropping frequency, crop type, and fertiliser after 37 years, Volume 86 number 4. In: Canadian Journal of Soil Science.

[3] Carmassi, G., et al., (2005). Modelling salinity build up in recirculating nutrient solution culture. J. Plant Nutrition. 28, 431-445.

https://doi.org/10.1081/PLN-200049163

[4] Cutolo. Silvana A (2012). "Parasitological risk assessment from wastewater reuse for disposal in soil in developing countries", Water Science \& Technology, 03/2012.

[5] Environment Protection Act, (1991). Drinking Water Standards.

[6] Fernandez. D, 2009. Static hydroponic systems cons and pros. Available from: http://www.allhydroponics [Accessed 15 January, 2010].

[7] Gagnon. V, G. Maltais-Landry, J.Puigagut, F. Chazarenc \& J. Brisson (2010). Treatment of Hydroponics Wastewater Using Constructed Wetlands in Winter Conditions. Water Air Soil Pollution 483-490.

https://doi.org/10.1007/s11270-010-0362-8

[8] Keller, R., Perim, K., Semionato, S., Zandonade, E., Cassini, S. \& Goncalves, R. F. (2005). Hydroponic cultivation of lettuce (Lactuca sativa) using effluents from primary, secondary and tertiary p UV treatments. Water Sci. Technol. Water Supply 5(1), 95-100.

[9] Mkude, IT, and J Saria (2014). Assessment of waste stabilization ponds (WSP) efficiency on wastewater treatment for agriculture reuse and other activities a case of Dodoma municipality, Tanzania", Ethiopian Journal of Environmental Studies and Management.

[10] Passam, H.C.,(2008). The fruiting species of the Solanaceae. Eur. Journal of Plant Science and Biotechnology 2, 1-2.

[11] Rouphael, Y., G. Colla, A. Battistelli, S. Moscatello, S. Proietti, and E. Rea. 2004. Yield, water requirement, nutrient uptake and fruit quality of zucchini squash grown in soil and closed soilless culture. Journal of Horticultural Science \& Biotechnology 79: 423-430.

https://doi.org/10.1080/14620316.2004.11511784

[12] Savvas Dimitrios and Gizas George (2002b). Response of hydroponically grown gerbera to nutrient solution recycling and different nutrient cation ratios, Department of Floriculture and Landscape Architecture, Faculty of Agricultural Technology.

[13] Tattini. M. Florence, (1993). International Symposium on Horticultural Substrates other than Soil in Situ, Italy. In: Acta Horticulture, Number 342, pp 86, 303-305.

[14] Varlagas et al., (2010), Modelling uptake of $\mathrm{Na}+$ and $\mathrm{Cl}$ - by tomato in closed cycle cultivation systems as influenced by irrigation water salinity. Agricultural water management

https://doi.org/10.1016/j.agwat.2010.03.004 